\title{
O que a medicina social latino-americana pode contribuir para os debates globais sobre as políticas da Covid-19: liçóes do Brasil
}

| ${ }^{1}$ Francisco Ortega, ${ }^{2}$ Dominque P. Behague |

1 Instituto de Medicina Social, Universidade do Estado do Rio de Janeiro. Rio de Janeiro-RJ, Brasil (fjortega2@gmail.com). ORCID: 0000-0002-5039-9449

${ }^{2}$ Center for Medicine, Health \& Society, Vanderbilt University, USA; Department of Global Health and Social Medicine, King's College London. United Kingdom. ORCID: 0000-0001-8621-6942

Recebido em: 20/04/2020

Aprovado em: 25/04/2020

Revisado em: 28/04/2020

DOI: http://dx.doi.org/10.1590/S0103-73312020300205

\section{"Preparatividade"}

Dois meses antes de o primeiro caso de Covid 19 ser reportado em Wuhan, na província de Hubei, China, em $1^{\circ}$ de dezembro de 2019, o Global Health Security Index, compilado pela Nuclear Threat Initiative e pela Escola de Saúde Pública da Johns Hopkins University, publicava um informe que ranqueava 195 países em função de sua "preparatividade" (preparedness) ${ }^{1}$ para enfrentar uma pandemia, como a da Covid-19. Nesse ranking, os Estados Unidos ocupavam o primeiro lugar, e o Reino Unido, o segundo. Coreia do Sul ocupava o $9^{\circ}$, Brasil o $22^{\circ}$, Singapura o $24^{\circ}$ e China o 51 (GHSI, 2019; DALGLISH, 2020).

Quando olhamos esse ranking seis meses após sua publicação, as predições não poderiam ser mais equivocadas. Estados Unidos e Reino Unido têm produzido respostas desastrosas à epidemia, envolvendo omissóes criminosas, difusão de fakenews, confusôes e adiamentos das medidas necessárias quase criminosos. Nenhum dos dois países parece ter o equipamento necessário de proteção de profissionais, nem número suficiente de leitos hospitalares e de UTI.

Hoje, 20 de abril de 2020, o primeiro contabiliza 765.128 casos e 40.592 mortes, e o segundo, 120.067 casos e 16.060 mortes. ${ }^{2}$ Diante desses resultados, não surpreende 
que a revista Foreign Policy tenha definido a Covid-19 como a "pior falha de inteligência da história dos Estados Unidos” (ZENKO, 2020). Por outro lado, naçôes asiáticas como Coreia do Sul, Singapura, Taiwan e China têm desenvolvido as respostas mais rápidas e eficazes para conter o avanço da pandemia (DALGLISH, 2020).

A nova forma de racionalidade que encarna a "preparatividade" tem contribuído para redefinir a saúde global como campo biopolítico (LYNTERIS, 2018). "Preparatividade" é um conceito-chave na Antropologia e nas humanidades médicas que remete à análise crítica de novas abordagens epidemiológicas e de saúde pública para antecipar e se preparar diante de epidemias de doenças infeciosas (LAKOFF, 2007; 2017). Todavia, a pandemia de Covid-19 tem revelado uma grave falha na "preparatividade" desses países. As consequências para a saúde global são importantes: artigo recente da Lancet revela que 85 \% de todas as organizaçóes de saúde têm suas sedes em países do Norte Global e a metade dos líderes de saúde global são cidadãos de Estados Unidos e Reino Unido. E ainda, o que é mais sério, modelos de saúde global baseiam-se em assistência técnica e capacitação realizada por esses países, cuja resposta à pandemia tem sido "esclerótica e atrasada, na melhor das hipóteses" (DALGLISH, 2020). Os motivos das falhas na "preparatividade" para a pandemia são de natureza diversa e não são objeto deste texto. Instituiçôes de saúde pública concebem "preparatividade" a partir de métricas para mitigar a mortalidade.

Em contraste com uma compreensão tecnocrática e gerencial da saúde pública global, sugerimos aqui algumas maneiras pelas quais o campo da Medicina Social, especificamente na América Latina, pode fortalecer o impacto do papel da Medicina e da Saúde Pública na pandemia (BIRN; MUNTANER, 2019; BREILH, 2019; MENDES et al., 2017). Quando falamos do campo da Medicina Social latinoamericana, estamos nos referindo, no caso do Brasil, ao campo da Saúde Coletiva (OSMO; SCHRAIBER, 2017; VIEIRA DA SILVA; PINELL, 2014). Acreditamos que essa perspectiva mais abrangente englobaria, por um lado, a análise das condiçôes sociais que impedem ou aumentam as iniciativas de mitigação da mortalidade e que passariam pelo fortalecimento dos sistemas de saúde com foco na Atenção Primária, claras diretrizes para triagem de casos e até intervençôes socioeconômicas e de saúde pública que diminuam as disparidades de classe e de raça e seus impactos na saúde. Por outro lado, os debates gerados atualmente sugerem a necessidade de avançar muito mais nessa agenda "social", repensar lógicas, valores e mercados neoliberais, 
e seu impacto prejudicial sobre os sistemas de saúde e, mais amplamente, sobre a geopolítica da elaboração de políticas globais (ALAMES, 2020).

\section{Achatar a curva}

As medidas da Organização Mundial da Saúde (OMS) para "achatar a curva" e controlar a expansão da Covid-19 enquanto não se disponha de tratamento ou vacina incluem distanciamento social (chegando ao lockdown em alguns países e regiôes), ampliação de testagem e seguimento de casos positivos, medidas higiênicas, proteção de profissionais de saúde e aprimoramento e aumento de leitos hospitalares e de UTI. A maioria dessas medidas não é viável para grande parte da população do Sul Global. Além do mais, mesmo sendo necessárias, essas medidas provocarão uma crise econômica e sociopolítica enorme, levando à pobreza extrema e a um elevado número de mortes.

O caso extremo é a Índia, onde o Ministério da Saúde declarava, em meados de março, que a crise da Covid-19 não representava uma "emergência de saúde" (BUKHARI, 2020), e no dia 24 do mesmo mês, sem aviso nem preparaçáo, o premiê Narendra Modi ordenou um confinamento repentino, que provocou enormes fluxos populacionais de migração reversa de milhares de trabalhadores e suas famílias, que tiveram que caminhar centenas de quilômetros a pé para voltar a seus povoados. O lockdown indiano tem sido definido como "a maior migração humana a pé desde a partição” do país em 1947, resultando em caos, desabastecimento, fome e muitas mortes, especialmente nas comunidades mais marginalizadas (DANUYAL, 2020; HRW, 2020).

Em contextos socioeconômicos vulneráveis, políticas de lockdown indiscriminado podem exacerbar e aprofundar as desigualdades de saúde persistentes. Nesse sentido, recente editorial de Lancet recomenda que cada sociedade identifique e dê suporte aos grupos considerados mais vulneráveis. Se esses grupos não são devidamente identificados e assistidos, as consequências da pandemia serão mais devastadoras, levando ao aprofundamento das desigualdades em saúde (EDITORIAL, 2020). No Brasil, essa situação afeta particularmente os moderadores das favelas nas grandes cidades. Como diz um líder comunitário de Paraisópolis, uma das maiores favelas da cidade de São Paulo, "esse isolamento é um isolamento para 'gringo ver', para rico. O pobre não tem condição de fazer” (GUIMARÃES, 2020). 


\section{Global/local}

No campo da saúde global, críticas às iniciativas de cima para baixo e apelos a "generalizar" (scaling up) e replicar intervençôes em contextos diferentes têm sido frequentes (ADAMS; BURKE; WHITMARSH, 2014). No campo da saúde mental global, por exemplo, o argumento da natureza neurobiológica dos transtornos psiquiátricos, que afetaria igualmente todos os indivíduos em todas as culturas, tem sido invocado para justificar a escalonabilidade e generalização do uso de psicoestimulantes, bem como a exportação de conhecimentos psiquiátricos ocidentais e pacotes de cuidados padronizados para o Sul Global. Os críticos argumentam que tais abordagens promovem intervençôes de "tamanho único" (one-size-fits-all) que pressupóem sua aplicabilidade global e, portanto, diminuem os marcadores de diferença como classe, gênero, raça, etnia ou cultura, resultando na rápida expansão do diagnóstico e das soluçôes farmacêuticas (MILLS, 2014). Iniciativas desse tipo contribuem para exportar modelos ocidentais de doença e tratamento, subestimam o papel dos praticantes da medicina tradicional, ignoram a variabilidade cultural na avaliação e resposta ao sofrimento mental, que é medicalizado, e negligenciam suas causas sociais e econômicas em países de baixa e média renda (ORTEGA; WENCESLAU, 2020). Neste e em outros exemplos, o "global" efetivamente se equipara ao domínio da formulação de políticas liderada pelos ideais e expertise em países do Norte Global, frequentemente endossados de maneira oficial pela OMS, e o "local" se identifica com as experiências de base no Sul Global, que geralmente não cumprem os objetivos e padrões da política global (ADAMS et al., 2019; BÉHAGUE; STORENG, 2013).

O modelo de "tamanho único" ecoa em iniciativas de achatamento da curva que replicam as mesmas medidas sanitárias e modelos epidemiológicos com pouca ou nenhuma consideração dos diferentes contextos locais. No caso de países como Índia ou Brasil, as medidas de tamanho único e de cima para baixo não levam em consideração as condiçôes de vida e outras características das comunidades para as quais se destinam, e por isso dificilmente conseguem conter a propagação do vírus em países com níveis táo elevados de pobreza e desigualdade. É necessário mobilizar autoridades de saúde pública e a sociedade civil, para que as diferentes comunidades desenvolvam suas próprias estratégias de autoproteção. Só com o envolvimento desses 
grupos no desenho e implementação, medidas de saúde pública poderão funcionar em contextos de extrema pobreza e vulnerabilidade (JANA, 2020).

No entanto, intervençôes que são efetivas em determinado local não são necessariamente traduzíveis para outros locais; mas quando são, são necessários um conhecimento íntimo e uma resposta sensível às diferenças entre os contextos, o que é muito diferente de apelos que generalizam modelos de "tamanho único" (ADAMS; BURKE; WHITMARSH, 2014). Examinar as especificidades locais e históricas dos diferentes contextos, assim como organizar os sistemas de saúde e práticas dos profissionais tornam as políticas de saúde global e os modelos epidemiológicos significativos em contextos particulares. Essa análise exige ir além da mera adaptação de práticas baseadas em evidências a diferentes realidades locais; requer a produção de "evidências localmente relevantes" para promover as "melhores práticas e estratégias de intervenção", levando sempre em consideração a experiência situada contextualmente (KIENZLER; LOCKE, 2017, p. 293).

Apesar de local e global serem frequentemente conceitualizados como esferas distintas, é necessário ir além dessa polarização global/local, como ilustra a frutífera teorização em antropologia, por exemplo, nas noçôes de "glocalidade" (ESCOBAR, 2001), "fricção" (TSING, 2005) ou "montagens globais" (global assemblages, COLLIER; ONG, 2005). Essas noçóes evidenciam que discriminar local e global é menos importante do que atentar para o fato de as forças que se combinam e conspiram para produzir desigualdades serem complexas e específicas às histórias, geografias e práticas sociais particulares. Estas são, ao mesmo tempo, locais e globais (ADAMS et al., 2009).

Voltando ao caso de Covid-19, suposiçôes de longa data sobre o que é global e local, e onde estão situados, estão sendo viradas de cabeça para baixo. Com vários países asiáticos assumindo a liderança na demonstração do que é uma política eficaz de contenção da pandemia, estamos testemunhando um destronamento do papel central que os especialistas da Europa Ocidental e da América do Norte desempenham há muito tempo junto à OMS. A sede do "global" está potencialmente em processo de des-ocidentalização. Simultaneamente, os EUA estão no epicentro da pandemia, lutando para implementar medidas básicas de contenção (com estados e municípios competindo encarniçadamente por recursos escassos), apesar de serem tecnológica e economicamente "avançados". Lança-se assim mais luz do que nunca sobre a necessidade de ir além dos pressupostos desenvolvimentistas das relaçóes 
entre economia e saúde (ESCOBAR, 2018). As interdependências de diferentes "locais" e a necessidade de maior colaboração dentro e fora das fronteiras nacionais estão reformulando o "local" de novas maneiras.

\section{Um tamanho não serve para todos}

No combate à pandemia, "um tamanho não serve para todos" (one size does not fit all), o que exige alternativas realistas e viáveis de enfrentamento da Covid-19 no Sul Global. Glassman, Chalkidou e Sullivan propóem começar com água e saneamento; proteger outros serviços essenciais de saúde (por exemplo: vacinaçáo, controle da malária) e fornecer transferências de renda que permitam o distanciamento social. Existem também outras recomendaçôes consistentes com as orientaçôes da OMS, mas com prioridades diferentes para esses países, tais como a proteção da força de trabalho em saúde, testagem dirigida a grupos específicos e uso de dados nacionais e subnacionais reais para informar modelos epidemiológicos (GLASSMAN; CHALKIDOU; SULLIVAN, 2020).

Apesar dos recursos limitados, alguns países africanos adotaram medidas interessantes para limitar a propagação do vírus, incluindo estratégias simplificadas de triagem e rastreamento proativo em Uganda, chatbots de WhatsApp que fornecem informaçôes confiáveis e rápidos resultados de testes diagnósticos no Senegal, e estaçôes de lavagem de mãos nos centros de transporte em Ruanda (DALGLISH, 2020).

A situação no Brasil é muito complexa. Governos estaduais dos principais estados introduziram medidas de distanciamento social consistentes com as diretrizes da OMS. No entanto, o presidente Bolsonaro tem continuamente minimizado o que denomina de "histeria" com o coronavírus, ou "gripezinha", incentivando a suspensão das medidas de isolamento e a volta da população às ruas, promovendo o que denomina de "isolamento vertical", restrito às populaçôes de maior risco (NYT, 2020; ORTEGA; ORSINI, 2020). Essa situação tem provocado uma crise política e tensóes com os governadores dos estados e com o Ministério da Saúde, o que limita a aplicação das medidas e a aceitação da população. Diferentemente da situação de muitos países do Sul Global, o Brasil tem um Sistema Único de Saúde (SUS), que garante acesso quase universal aos serviços de saúde. Trinta anos após sua implementação, o SUS sofre permanentes desigualdades geográficas, financiamento insuficiente e colaboração precária entre os setores público e privado (CASTRO et al., 2019). 
À semelhança de muitos países de renda baixa e média, 13,5 milhóes de brasileiros se encontram em situação de extrema pobreza. Nas favelas das grandes cidades vivem 13,6 milhóes de pessoas espremidas em casas e barracos ligados por vielas, sem saneamento e acesso a água limpa. Somente no Nordeste do Brasil, 12 milhóes de moradores não tiveram acesso diário à água encanada em 2018; 72\% das famílias nessas comunidades não têm economias nem para resistir uma semana. O país tem 38,3 milhóes de brasileiros com empregos precários, e a renda básica emergencial (RBE) de R \$ 600 a trabalhadores informais, autônomos e em contrato intermitente, a ser paga por três meses durante a pandemia do novo coronavírus, é insuficiente. Em tais circunstâncias, análogas às de muitos países do Sul Global, distanciamento social, lavagem das mãos e outras medidas de saúde pública não são viáveis e podem até ser prejudiciais, ao aumentar as desigualdades sociais em saúde (GUIMARÁES, 2020).

No entanto, uma dificuldade com a crítica "um tamanho não serve para todos" é que ela situa, principalmente, as políticas desenvolvidas por instituiçōes, atores e governos do Norte Global como o ideal com o qual as "necessidades" infraestruturais de outros países são identificadas. A urgência da situação reforça compreensivelmente essa suposição, mas também é importante reconhecer que a crítica "um tamanho não serve para todos" exclui reflexôes mais profundas e colaboraçôes não apenas internacionais, mas colaboraçôes inter-regionais entre estados e municípios, que atravessam as fronteiras nacionais e que são necessárias (ALAMES, 2020)

\section{Ajuda mútua e transformação estrutural}

Em contextos de vulnerabilidade socioeconômica, em que o sistema mostra sua fraqueza, traficantes e milicianos em diversas regióes do país se apresentam como provedores da lei e da ordem, aplicando medidas de distanciamento social, incluindo toques de recolher rigorosos para controlar a propagação do coronavírus (SCHIPANI; HARRIS, 2020). Inclusive, o Governo Federal prepara uma estratégia de combate ao novo coronavírus nas favelas brasileiras, que buscará amparo de lideranças ligadas ao tráfico de drogas e à milícia. Nessas áreas, onde "o Estado está ausente" nas palavras do ex-ministro de Saúde Henrique Mandetta, "a Saúde dialoga, sim, com o tráfico, com a milícia, porque também são seres humanos e precisam colaborar, ajudar, participar" (GLOBO, 2020).

Wenzel Geissler cunhou o termo "para-Estado" (para-state) em relação aos contextos de ausência ou presença limitada do Estado, em que este permanece 
presente e potente, "se não sempre no controle ou cumprindo expectativas legítimas de controle” (GEISSLER, 2015, p. 2). Nesses contextos paraestatais vêm surgindo novas formas de ativismo solidariedade e "ajuda mútua" para mobilização e sobrevivência (SPADE, 2020), algumas através de estruturas de ONGs preexistentes, e outras criando do zero novas relaçôes e redes sociais.

No Complexo do Alemão, bairro que abriga um dos maiores conjuntos de favelas da Zona Norte do município do Rio de Janeiro, diversos coletivos se reúnem desde 2013 para monitorar e denunciar problemas do território. Os coletivos "Juntos pelo Complexo do Alemão" se uniram com outras comunidades para combater expansão da Covid-19 nas favelas brasileiras. Entre as medidas propostas, encontram-se o apoio para pressionar o poder público para promover maior quantidade de testes nas favelas e os encaminhamentos devidos dos casos confirmados; apoio material para criação de estratégias de comunicação direta, feita por comunicadores locais com linguagens próprias para grupos específicos: cartazes informativos, lambe-lambe, carros de som e material para circular nas redes internas de WhatsApp; procura de caminhos de atendimentos psicológicos para o tratamento da população favelada; medidas para evitar o aumento da repressão das forças policiais e a estigmatização e culpabilização dos moradores das favelas pela expansão da pandemia (ALEMÃO, 2020).

Em sintonia com diversas medidas propostas pelo coletivo do Alemão, a Central Única de Favelas (CUFA), ONG fundada no Rio de Janeiro em 1999, apresentou 14 recomendaçóes para limitar o impacto da pandemia nas favelas brasileiras. As recomendações englobam a distribuição gratuita de água, sabão, álcool $70^{\circ} \mathrm{em}$ gel e água sanitária; organização em mutirôes das centrais de abastecimento para a distribuição de alimentos durante a quarentena; aluguel de pousadas ou hotéis para idosos e grupos vulneráveis; instituição de Programa de Renda Mínima para as famílias já inscritas no Cadastro Único e adicional de renda para os cadastrados no Bolsa Família; incentivo para que a população compre dos pequenos comerciantes; liberação de pontos de internet junto às empresas de fibra ótica; criação de rede de comunicação com apoio técnico do Ministério da Saúde para filtrar e verificar em tempo real as informaçóes compartilhadas em redes sociais para as favelas; ampliação das equipes de Saúde da Família (CUFA, 2020).

Grupos de ajuda mútua são um potencial aliado da medicina social, porque muitas vezes são capazes de permitir o engajamento político de base (eles explicitamente promovem a educação política), além de cobrir o básico da organização da circulação 
de bens e serviços para o bem de todos. Ao contrário dos grupos de caridade, eles também parecem ler a teoria social, o que é bem diferente.

\section{Conclusão}

Quando examinamos as diferentes respostas populares que vêm se desenrolando no Brasil, em particular nas favelas do Rio de Janeiro, constatamos que algumas dessas iniciativas fazem mais do que fornecer ajuda como um ato de caridade e não estão simplesmente preenchendo lacunas onde o Estado falha. As iniciativas de ajuda mútua constroem capacidade de auto-organização e autodeterminação e mantêm o potencial de gerar novas infraestruturas, mobilizando um grande número de pessoas para não apenas exigir reformas ou igualdade de direitos, mas desestabilizar as relaçóes paternalistas com o Estado e transformar desigualdades institucionalizadas e suas causas históricas.

Pensar políticas e intervençóes de saúde global para enfrentar a pandemia de Covid-19 em contextos de extrema vulnerabilidade exige ir além de medidas de "tamanho único" e de cima para baixo que desconsideram as condiçóes de vida dos indivíduos para os quais essas medidas são destinadas, e envolver esses grupos em seu desenho e implementação para garantir sua efetividade nesses locais. Para tanto, é imperativo a análise cuidadosa das especificidades históricas e culturais desses contextos e as experiências situadas dos indivíduos para produzir evidências relevantes e intervençôes adequadas para esses grupos.

Com a geopolítica da saúde global mudando a cada dia, a saúde pública está em uma posição única para elucidar a crítica do capitalismo que há muito se desenvolve na medicina social latino-americana e na Saúde Coletiva brasileira. Existem fortes evidências dos pontos fortes e resultados satisfatórios de melhoria da saúde da população quando a medicina social, e não o desenvolvimento econômico governam em nível local, com mecanismos que garantem inclusão, responsabilidade democrática e orçamento participativo (LAURELL, 2003). Como os autores associados à Asociación Latinoamericana de Medicina Social (ALAMES) argumentaram, muitos estão culpando o vírus pela crise econômica, mas isso é parcialmente impreciso, pois nunca nos recuperamos da crise de 2008 e alguns países do Norte Global - principalmente os EUA - são particularmente hábeis em ocultar as desigualdades de renda e saúde, as quais continuam aumentando. A medicina 
social latino-americana tem o potencial para deslocar a conversa para além de uma abordagem clássica de "determinantes sociais da saúde", na medida em que assumiu uma posição vigorosa em relação à imposição global, via política de desenvolvimento ditada no Norte, de modelos capitalistas desenfreados de desenvolvimento para os países do Sul Global.

\section{Referências}

ADAMS, V. et al. Re-imagining global health through social medicine. Global Public Health, v. 14, n. 10, p. 1383-1400, 2019.

ADAMS, V.; BURKE, N. J.; WHITMARSH, I. Slow Research: Thoughts for a Movement in Global Health. Medical Anthropology, v. 33, n. 3, p. 179-197, 2014.

ALAMES. Asociación Latinoamericana de Medicina Social y Salud Colectiva. Alames against the pandemic covid-19. 1 abr. 2020. Disponível em: <https://phmovement.org/wp-content/ uploads/2020/04/ENG-ALAMES-AGAINST-THE-PANDEMIC-COVID-19.pdf> . Acesso em: 16 abr. 2020.

ALEMÃO. Juntos pelo Complexo do Alemão. Carta aberta sobre o coronavirus nas favelas. 26 mar. 2020. Disponível em: <https://docs.google.com/document/ d/1GNBBigO2ewVxRuLNJM17Wkxodh0_BsFRB4398bufbgE/edit?fbclid=IwAR1oFMIG PloKxRop70sHf9B60cQtGg1FMVbU0N6NfeFnoCsHTSRhXT3aC4I>. Acesso em: 14 ab. 2020.

BÉHAGUE, D. P.; STORENG, K. T. Pragmatic politics and epistemological diversity: the contested and authoritative uses of historical evidence in the Safe Motherhood Initiative. Evidence \& Policy: A Journal of Research, Debate and Practice, v. 9, n. 1, p. 65-85, 2013.

BIRN, A. E.; MUNTANER, C. Latin American social medicine across borders: SouthSouth cooperation and the making of health solidarity. Global public health, v. 14, n. 6-7, p. 817-834, 2019.

BREILH, J. Critical Epidemiology in Latin America: Roots, Philosophical and Methodological Ruptures. In: VALLVERDÚ J.; PUYOL, A.; ESTANY, A. (Org.) Philosophical and Methodological Debates in Public Health. Cham: Springer, 2019. p. 21-45.

BUKHARI, A. A Índia está à beira de uma catástrofe - e o governo de extrema-direita será o responsável. Jacobin Brasil. 9 abr. 2020. Disponível em: <https://jacobin.com.br/2020/04/aindia-esta-a-beira-de-uma-catastrofe-e-o-governo-de-extrema-direita-sera-o-responsavel/> Acesso em: 12 abr. 2020.

CASTRO, M. C. et al. Brazil's unified health system: the first 30 years and prospects for the future. Lancet, v. 394, n. 10195, p. 45-356. Doi: 10.1016/S0140-6736(19)31243-7. 
COLLIER, S.; ONG, A. Global Assemblages, Anthropological Problems. In: COLLIER, S.; ONG, A. (Org.). Global Assemblages: Technology, Politics, and Ethics as Anthropological Problems. Malden, MA: Wiley-Blackwell, 2005. p. 3-21.

CUFA (2020). 14 propostas para reduzir o impacto do Corona Virus nas Favelas. 20 mar. 2020. Disponível em: <https://ciclovivo.com.br/vida-sustentavel/bem-estar/14-propostascoronavirus-favelas/> Acesso em 12 abr. 2020.

DALGLISH, S. L. COVID-19 gives the lie to global health expertise. Lancet. 26 mar. 2020. pii: S0140-6736(20)30739-X. Doi: 10.1016/S0140-6736(20)30739-X.

DANIYAL, S. Not China, not Italy: India's coronavirus lockdown is the harshest in the world. Schroll.in. 3 ab. 2020. Disponível em: <https://scroll.in/article/957564/not-china-not-italyindias-coronavirus-lockdown-is-the-harshest-in-the-world>. Acesso em: 16 abr. 2020.

EDITORIAL. Redefining vulnerability in the era of COVID-19. Lancet, 395, n. 10230, P1089, 4 ab. 2020. April, 4. doi.org/10.1016/S0140-6736(20)30757-1

ESCOBAR, A. Designs for the pluriverse: Radical interdependence, autonomy, and the making of worlds. Durham: Duke University Press, 2018. 312 p.

GEISSLER, P. W. Introduction: A Life Science in Its African Para-State. In: GEISSLER P. W. (org.) Para-States and Medical Science: Making African Global Health. Durham (NC): Duke University Press, 2015. p. 1-46.

GHSI. (2019). Global Health Security Index. Building Collective Action and Accountability. Outubro. Nuclear Threat Initiative and Center for Health Security. Bloomberg School of Public Health. Johns Hopkins University. Disponível em https://www.ghsindex.org/wp-content/ uploads/2020/04/2019-Global-Health-Security-Index.pdf. Acesso em: 15 abr. 2020.

Glassman, A.; CHAlKIDOU, K.; SUllivan, R. Does One Size Fit All? Realistic Alternatives for COVID-19 Response in Low-Income Countries. Center for Global Development. 2 ab. 2020. Disponível em <https://www.cgdev.org/blog/does-one-size-fit-all-realisticalternatives-covid-19-response-low-income-countries>. Acesso em: 12 abr. 2020.

OGLOBO. "Saúde dialoga com tráfico e milícia”, diz Mandetta. O Globo. 8 abr. 2020. Disponível em: https://oglobo.globo.com/rio/saude-dialoga-com-trafico-milicia-diz-mandetta-24361014 . Acesso em: 14 abr. 2020.

GUIMARÃES, L. Favelas serão as grandes vítimas do coronavírus no Brasil, diz líder de Paraisópolis. BBC News Brasil. 18 mar. 2020. Disponível em: <https://noticias.uol.com.br/ ultimas-noticias/bbc/2020/03/18/favelas-serao-grandes-vitimas-do-coronavirus-no-brasil-dizlider-de-paraisopolis.htm??cmpid=copiaecola> Acesso em: 15 abr. 2020.

HRW. India: COVID-19 Lockdown Puts Poor at Risk. Human Rights Watch, 27 mar. 2020. Disponível em: <https://www.hrw.org/news/2020/03/27/india-covid-19-lockdown-puts-poorrisk>. Acesso em 14 ab. 2020 
JANA, S. Can India Contain the Pandemic? Scientific American. 4 ab. 2020. Disponível em: $<$ https://blogs.scientificamerican.com/observations/can-india-contain-the-pandemic/>. Acesso em: 16 abr. 2020.

KIENZLER, H.; LOCKE, P. The Effects of Societal Violence in War and Post-War Contexts. In: WHITE, R. G. et al. (Org.) The Palgrave Handbook of Sociocultural Perspectives on Global Mental Health. London: Palgrave Macmillan, 2017. p. 285-305.

LAKOFF, A. Preparing for the Next Emergency. Public Culture, v. 19, n. 2, p. 247-271, 2007. . Unprepared: Global Health in a Time of Emergency. Berkeley: University of California Press, 2017. 240 p.

LAURELL, A. C. What does Latin American social medicine do when it governs? The case of the Mexico City government. American Journal of Public Health, v. 93, n. 12, p. 2028-2031, 2003.

LYNTERIS, C. Andrew Lakoff's Unprepared: Global Health in a Time of Emergency. Somatosphere. 24 abr. 2018. Disponível em: <http://somatosphere.net/2018/andrew-lakoffsunprepared.html/>. Acesso em: 17 abr. 2020.

MENDES, A. et al. A contribuição do pensamento da saúde coletiva à economia política da saúde. Saúde e Sociedade, v. 26, n. 4, p. 841-860, 2017.

MILLS, C. Psychotropic Childhoods: Global Mental Health and Pharmaceutical Children. Children \& Society, v. 28, n. 3, p. 194-204, 2014.

NYT. Bolsonaro Urges Brazilians Back to Work, Dismisses Coronavirus "Hysteria”. The New York Times, 24 mar. 2020. Disponível em: <https:/www.nytimes.com/reuters/2020/03/24/ world/americas/24reuters-health-coronavirus-brazil.html> Acesso em: 13 abr. 2020.

ORTEGA, F.; ORSINI, M. Governing COVID in Brazil: Dissecting the Ableist and Reluctant Authoritarian. Somatosphere. Series: Dispatches from the Pandemic. 17 ab. 2020. Disponível em: <http://somatosphere.net/2020/governing-covid-in-brazil-dissecting-the-ableist-andreluctant-authoritarian.html/>. Acesso em: 18 abr. 2020.

ORTEGA, F.; WENCESLAU, L. D. Challenges for implementing a global mental health agenda in Brazil: The "silencing" of culture. Transcultural Psychiatry, v. 57, n. 1, p. 57-70, 2020.

OSMO, A.; SCHRAIBER, L. B. O campo da Saúde Coletiva no Brasil: definiçôes e debates em sua constituição. Saúde e Sociedade, v. 24, supl. 1, p. 205-218, 2015.

SCHIPANI, A.; HARRIS, B. Drug gangs in Brazil's favelas enforce coronavirus lockdown. Financial Times. 27 mar. 2020. Disponível em: <https://www.ft.com/content/aaef1591-2fc54e6f-ab84-0e83b5a146ca>. Acesso em: 12 abr. 2020.

SPADE, D. Solidarity Not Charity: Mutual Aid for Mobilization and Survival. Social Text, v. 38, n. 1(142), p. 131-151, 2020. 
TSING, A. L. Friction: An ethnography of global connection. Princeton, NJ: Princeton University Press, 2005. $344 \mathrm{p}$.

VIEIRA-DA-SILVA, L. M.; PINELL, P. The genesis of collective health in Brazil. Sociology of Health \& Illness, v. 36, n. 3, p. 432-446, 2014.

ZENCO, M. The Coronavirus Is the Worst Intelligence Failure in U.S. History. Foreign Policy, 25 mar. 2020. Disponível em: <https://foreignpolicy.com/2020/03/25/coronavirus-worstintelligence-failure-us-history-covid-19/>. Acesso em: 13 abr. 2020.

\section{Notas}

${ }^{1}$ Preparadness remete ao "estado de preparação", ao "estar preparado". "Preparação" não chega a captar o significado pleno. Optamos por "preparatividade", conscientes de que a palavra "fere os ouvidos".

${ }^{2}$ https://www.worldometers.info/coronavirus/? 